' Gangadharam PRJ, Devadatta S, Fox W, Narayanan Nair C, Selkon JB. Rate of inactivation of isoniazid in South Indian patients with pulmonary tuberculosis. Bull WHO $1961 ; 25: 793-806$.

${ }^{8}$ Data sheet. Rifadin. Lepetit Pharmaceuticals Ltd.

${ }^{9}$ Data sheet. Rimactane. Ciba Laboratories.

10 Siegler DI, Bryant M, Burley DM, Citron KM, Standen SM. Effect of meals on rifampicin absorption. Lancet 1974 ;ii:197-8.

${ }^{11}$ Donomae I, Yamamoto K. Clinical evaluation of ethambutol in pulmonary tuberculosis. Ann NY Acad Sci 1966;135:849-81.

${ }^{12}$ Doster B, Murray FJ, Newman R, Woolpert SF. Ethambutol in the initial treatment of pulmonary tuberculosis. Am Rev Respir Dis 1973;107: 177-90.

${ }^{13}$ Citron KM. Ethambutol: a review with special reference to ocular toxicity. Tubercle $1969 ; \mathbf{5 0}$ suppl:32.

14 Place VA, Thomas JP. Clinical pharmacology of ethambutol. Am Rev Respir Dis 1963;87:901-4.
15 Medical Research Council working party on tuberculosis of the spine. Sixth report. F Bone foint Surg 1978;60B:163-77.

16 Medical Research Council Tuberculosis Chemotherapy Trials Committee. Report to the MRC. Tubercle $1962 ; 43: 201-67$.

17 British Thoracic and Tuberculosis Association. Short course chemotherapy in pulmonary tuberculosis. Lancet 1975; i:119-24.

18 British Thoracic Association. Short course chemotherapy in pulmonary tuberculosis. Lancet $1980 ; 1: 1182-3$.

19 Gow JG. Genitourinary tuberculosis, a seven year review. $\mathrm{Br} \mathcal{F}$ Urol $1979 ; 51: 239-44$

${ }^{20}$ Devadatta S, Gangadharam PRJ, Andrews RJ, et al. Peripheral neuritis due to isoniazid. Bull WHO $1960 ; 23: 587-98$.

\title{
Survey of pulmonary tuberculosis in south and west Wales (1976-8)
}

\author{
R D H MONIE, A M HUNTER, KAREN ROCCHICCIOLI, JANINE WHITE, I A CAMPBELL, \\ G S KILPATRICK
}

\begin{abstract}
In routine clinical practice $20 \%$ of patients with pulmonary tuberculosis were treated with the regimen recommended by the British Thoracic Association after the British trial of short-course chemotherapy. Despite the use of several regimens that could be considered inadequate, no patient from the survey within south and west Wales appears to have relapsed yet. Deaths from pulmonary tuberculosis continue at the same rate as 10 years ago. Patient default remains a difficult problem even with modern, less toxic, short-course regimens.
\end{abstract}

\section{Introduction}

After the British Thoracic Association's short course chemotherapy trial, it was recommended that treatment with rifampicin (R) plus isoniazid $(\mathrm{H})$ for nine months, together with ethambutol (E) for the initial two months, should be accepted as standard chemotherapy for pulmonary tuberculosis in the United Kingdom. ${ }^{1}$ This regimen has the advantage of using less toxic drugs and reducing the period of chemotherapy required from 18 months to nine, thereby theoretically increasing the likelihood of good compliance.

To assess how widely the recommended regimen has been adopted, and with what results, we have carried out a retrospective survey of the management of cases of tuberculosis in parts of Wales.

Welsh National School of Medicine, Llandough Hospital, Penarth, S Glamorgan CF6 1 XX

$\mathrm{R}$ D H MONIE, MB, MRCP, lecturer in chest diseases

G S KILPATRICK, MD, FRCP, David Davies professor of tuberculosis and chest diseases

Department of Thoracic Medicine, Llandough Hospital, Penarth, S Glamorgan CF6 1XX

A M HUNTER, MB, MRCP, senior registrar

KAREN ROCCHICCIOLI, MB, MRCP, registrar (present appointment: research registrar, Wythenshawe Hospital, Manchester)

JANINE WHITE, MB, MRCP, registrar (present appointment: research fellow, Guy's Hospital, London)

I A CAMPBELL, MD, MRCP, consultant chest physician

\section{Methods}

The survey covered three years from 1 January 1976 to 31 December 1978 and included the five counties of south and west Wales, the population of which is just over 2 million. ${ }^{2}$

Cases of tuberculosis were traced from three sources: (1) the Hospital Activity Analysis forms, on which the diagnosis is recorded at the time of the patient's discharge from hospital; (2) the Mycobacterium Reference Unit of the Public Health Laboratory Service in Cardiff; and (3) the notification lists of patients with tuberculosis from the medical officers for environmental health.

A complete list of patients who had tuberculosis in the three-year period of the survey was made for each county, and the list circulated to the medical records officers of each hospital and chest clinic within that county. The hospital or chest clinic was visited, and the notes of each patient on the list were reviewed.

Information taken from the notes included: $(a)$ age and sex, $(b)$ the basis for the diagnosis of tuberculosis, $(c)$ the regimen prescribed and the duration of the treatment, $(d)$ how well the patient complied with treatment (poor drug compliance was registered if the physician supervising treatment recorded it in the patient's notes or if the patient failed to attend clinic on two or more occasions without good reason), $(e)$ number of deaths, $(f)$ side effects of drugs, and $(g)$ number of relapses.

\section{Results}

We reviewed the case notes of 753 patients.

Age and sex-Table I shows the number of cases of tuberculosis within each age group and the incidence of tuberculosis related to the age of the population: $72 \%$ of the patients were male, and $6.4 \%$ of all patients were non-Caucasian.

Basis for diagnosis-Mycobacterium tuberculosis was cultured from the sputum in 588 patients $(78 \%)$, while $165(22 \%)$ were culture

TABLE I-Incidence of tuberculosis in South and West Wales

\begin{tabular}{|c|c|c|c|c|c|}
\hline \multirow{2}{*}{$\begin{array}{c}\text { Age } \\
\text { (years) }\end{array}$} & \multicolumn{3}{|c|}{ No of cases } & \multirow{2}{*}{$\begin{array}{l}\text { Percentage of } \\
\text { whole group }\end{array}$} & \multirow{2}{*}{$\begin{array}{l}\text { No of cases per } \\
100000 \text { of } \\
\text { population a year }\end{array}$} \\
\hline & Male & Female & Total & & \\
\hline $\begin{array}{c}0-4 \\
5-14 \\
15-44 \\
45-64 \\
65-74 \\
\geqslant 75\end{array}$ & $\begin{array}{r}12 \\
20 \\
143 \\
207 \\
102 \\
58\end{array}$ & $\begin{array}{r}6 \\
15 \\
80 \\
74 \\
16 \\
20\end{array}$ & $\begin{array}{r}18 \\
35 \\
223 \\
281 \\
118 \\
78\end{array}$ & $\begin{array}{r}2.4 \\
4.6 \\
29.6 \\
37.5 \\
15.7 \\
10.4\end{array}$ & $\begin{array}{r}4.9 \\
1.2 \\
8.9 \\
19.4 \\
20.4 \\
23.8\end{array}$ \\
\hline
\end{tabular}


negative. Of these 165 patients, histology was compatible with tuberculosis in 24, and 141 had chest radiographs showing changes suggestive of tuberculosis. Of these 141,82 had positive tuberculin test results, 23 had negative results, and 36 had no tuberculin test results recorded in the notes.

\section{TREATMENT REGIMENS}

Of the 753 patients reviewed, the case notes of 21 patients did not provide an accurate record of the treatment regimens, 19 patients $(2.5 \%)$ had atypical mycobacterial infections; and in 18 patients the diagnosis of tuberculosis was made after death (by necropsy in 15 and by positive cultures in the other three).

Eighty-nine patients died during chemotherapy. Thirteen deaths were thought to be directly attributable to pulmonary tuberculosis. A further 89 patients did not comply with treatment, of whom 10 subsequently received supervised treatment. Of 10 poor compliers who died, seven deaths were thought to be directly attributable to tuberculosis. Eighteen patients were participating in the current British Thoracic Association's trial of six months' chemotherapy. ${ }^{3}$

The above 254 patients were omitted from analysis. Table II shows the treatment regimens of the remaining 499 patients who completed chemotherapy. A total of 185 patients received ethambutol-isoniazid-

TABLE II-Treatment regimens for remaining 499 patients

\begin{tabular}{clrr}
\hline Regimen & & No & Percentage \\
\hline & R plus H with initial period of E or S & & \\
$1 *$ & 9 months & 16 & $3 \cdot 2$ \\
$2^{*}$ & $9-12$ months & 185 & $37 \cdot 1$ \\
& $\quad 12$ months & 143 & $28 \cdot 7$ \\
4 & E plus H with initial period of R or S & 38 & $7 \cdot 6$ \\
5 & $9-12$ months & 42 & $8 \cdot 4$ \\
6 & 18 months & 5 & $1 \cdot 0$ \\
7 & Regimens containing PAS & 2 & $0 \cdot 4$ \\
8 & RH with initial period of PAS & 4 & $0 \cdot 8$ \\
9 & PH with initial period of R & 54 & $10 \cdot 8$ \\
10 & Regimens with only two drugs & 3 & 0.6 \\
11 & Regimens with only one drug & 2 & $0 \cdot 4$ \\
12 & No chemotherapy & 5 & $1 \cdot 0$ \\
\hline & Regimen of R plus E & 499 & 100 \\
& & &
\end{tabular}

*Only 98 received ethambutol for two to three months.

$\mathrm{R}=$ Rifampicin. $\mathrm{H}=$ Isoniazid. $\mathrm{E}=$ Ethambutol. PAS = Para-aminosalicylic acid. $\mathrm{S}=$ Streptomycin.

rifampicin/isoniazid rifampicin (EHR/HR) or streptomycin-isoniazidrifampicin/isoniazid-rifampicin (SHR/HR) treatment for 9-12 months (regimen 2). Only $98(20 \%)$ received ethambutol for two to three months. When these figures were examined for each year of the survey it was found that $16 \%$ of patients in 1976 received treatment as recommended by the British Thoracic Association increasing to $21 \%$ in 1977 and $22 \%$ in 1978 . Of the remaining 87 patients, ethambutol was given to three patients for one month and to 60 for more than three months, while 24 received streptomycin as their third drug. Of the 16 who received $\mathrm{EHR} / \mathrm{HR}$ or $\mathrm{SHR} / \mathrm{HR}$ for under nine months (regimen 1), 11 were culture positive and five negative; $143(29 \%)$ received $\mathrm{EHR} / \mathrm{HR}$ or $\mathrm{SHR} / \mathrm{HR}$ for over 12 months (regimen 3).

Eighty patients were given rifampicin-isoniazid-ethambutol/ isoniazid-ethambutol $(\mathrm{RHE} / \mathrm{HE})$ or streptomycin-isoniazidethambutol/isoniazid-ethambutol (SHE/HE) treatment; 38 for nine months (regimen 4) and 42 for 18 months (regimen 5). Most of the 38 patients given this short course of treatment were culture positive. Fifty-eight were given isoniazid-ethambutol continuation treatment as a primary choice by the physician.

Eleven patients were given regimens containing para-aminosalicylic acid (PAS), and in six patients $\mathrm{PH}$ was used as continuation treatment (regimens 7 and 8). The inclusion of PAS appeared to be out of choice as none of the patients had either side effects to another drug or drug-resistant organisms.

Fifty-four patients received only two drugs with no initial period with a third drug (regimen 9). Thirty-two of these patients were culture negative, 30 were aged 15 years or under, and 37 were diagnosed as having primary tuberculosis on chest $x$-ray examination. Forty-five patients received isoniazid-rifampicin, eight received isoniazid-ethambutol, and one received $\mathrm{PH}$. One patient was subsequently found to have organisms resistant to isoniazid and, therefore, effectively had only ethambutol as chemotherapy.
Three patients received only one drug (regimen 10). Two (aged 5 and 6 years respectively) were thought after tuberculin skin test and chest $x$-ray examination to have primary tuberculosis. The third patient, a man of 64 with culture-positive pulmonary tuberculosis, received isoniazid alone after six weeks because of side effects to other drugs.

Two patients with culture-positive tuberculosis were not offered any treatment (regimen 11), one because the letter of referral to a chest physician went astray, and the other because the culture results appeared not to have been seen by the physician.

Five patients received ethambutol-isoniazid-rifampicin/ethambutolrifampicin (EHR/ER) treatment (regimen 12) for from 12 to 18 months. The isoniazid was stopped in one patient because of side effects and in the other four patients because of primary drug resistance to isoniazid.

\section{SIDE EFFECTS}

Seventy-six patients $(15 \%)$ had side effects from their treatment, but 35 could continue the same treatment either after a brief interruption or after desensitisation to the offending drug. Treatment was changed in the remaining 41 patients $(8 \%)$.

Side effects seen in patients receiving rifampicin and isoniazid included: asymptomatic rises in transaminases (18), jaundice (8), abdominal pains (2), Coomb's positive haemolytic anaemia (1), flu-like symptoms (2), pregnancy while taking oral contraceptive pill (1), and peripheral neuropathy (5). Three patients receiving ethambutol complained of blurred vision, but none had objective evidence of optic neuropathy. Four out of 11 patients receiving para-aminosalicylic acid had gastrointestinal upsets, while three patients had giddiness when taking streptomycin. Twenty-nine patients had drug rashes, fevers, or blood eosinophilias, but it was not clear from their case notes which drug was implicated.

\section{Discussion}

During the three-year period reviewed only 98 patients were treated with ethambutol-isoniazid-rifampicin/isoniazid-rifampicin for 9-12 months, the ethambutol being given for the initial two to three months. Thus only $20 \%$ of patients received the short-course regimen proved effective in the British Thoracic Association's trial and recommended in November 1976 as standard chemotherapy in the United Kingdom. ${ }^{1}$ The percentage so treated in our survey increased from $16 \%$ in 1976 to $21 \%$ in 1977 and $22 \%$ in 1978 . Most of the patients were managed by physicians who had participated in that trial, and it is surprising that so few have acted on its findings. Another 87 patients received isoniazid-rifampicin continuation treatment for 9-12 months with 24 being given streptomycin electively as the initial third drug and 60 receiving ethambutol for more than three months.

Isoniazid-ethambutol was used as continuation treatment in 80 patients $(16 \%)$, of whom 38 received rifampicin-isoniazidethambutol/isoniazid-ethambutol for only nine months. Many authorities would consider this to be inadequate chemotherapy, although, using a similar regimen, Lees $e t \mathrm{al}^{4}$ have reported no relapses one year after the end of treatment.

Thus $44.7 \%$ of patients received short-course chemotherapy (regimens 2 and 4, table II) in south and west Wales compared with $41 \%$ in Scotland during $1978^{5}$ and under $10 \%$ in the United States in $1979-80 .^{6}$

A further 143 patients $(28.7 \%)$ received ethambutol-isoniazidrifampicin/isoniazid-rifampicin for more than 12 months. All these patients were regular clinic attenders, and despite attending clinic between the ninth and 12th months chemotherapy was continued. This presumably means that several physicians in Wales remained unconvinced of the efficacy of short course chemotherapy.

It is interesting that para-aminosalicylic acid was electively used as part of continuation treatment in six patients $(1 \%)$. Four were adults, managed by chest physicians, and two were children with primary tuberculosis. 
Many physicians would accept that giving two drugs for an appropriate period to a patient with fully sensitive organisms would be adequate treatment. Most patients given two drugs, however, were assigned to such treatment before the sensitivities of the organisms were known. One patient proved to have resistant organisms and therefore received the equivalent of single-drug treatment. Of these 54 patients 37 had primary tuberculosis and, therefore, a presumed small bacterial population. Two children with primary tuberculosis received isoniazid alone, which many would consider inadequate treatment.

In their survey of pulmonary tuberculosis in Scotland, Heffernan $e t a l^{7}{ }^{8}$ reported that $4 \%$ of patients died of active disease, $2^{\prime} \%$ being diagnosed only after death. Ten years later, in our survey, mortality was similar $(5 \%)$ with $2 \%$ being diagnosed after death. In our survey $1.8 \%$ died from tuberculosis while taking chemotherapy, contrasting with $1.9 \%$ in Heffernan's study ${ }^{7}$ and $1.1 \%$ and $1.2 \%$ in two recent studies by the British Thoracic Association. ${ }^{3}{ }^{9}$

Fox and Mitchison ${ }^{10}$ claimed that with the introduction of short-course chemotherapy default by patients would be of much less consequence therapeutically. We classified 89 patients $(12 \%)$ as poor compliers, a very much higher figure than that seen in the two recent British Thoracic Association trials $5 \%$ and $\left.3 \%^{3}\right)$. This might imply that either better instructions, rapport, and doctor motivation are achieved in a trial, or that there may be some rejection of potential non-compliers from clinical trials. Of our 89 poor compliers, 43 were thought to have received a minimum of six months' treatment with 10 having supervised chemotherapy, although one of these patients did not receive his streptomycin because the district nurse considered it unnecessary. The British Thoracic Association's short-course study $^{1}$ suggested that $5 \%$ of patients receiving six months EHR/HR or SHR/HR would relapse, but surprisingly none of our poor compliers have relapsed as yet within this area of Wales. One patient, however, who reputedly had had at least 12 months' effective chemotherapy, had persistently positive sputum cultures.

Fox and Mitchison ${ }^{10}$ also suggested that with shorter-course chemotherapy more resources could be concentrated on persuading patients to attend for regular follow-up. It was disappointing to see that of the 89 defaulters, 36 had stopped attending clinic within six months, with little evidence in their case notes that any attempt had been made to persuade them to continue their treatment.

Side effects from treatment were experienced by $15 \%$ of patients. Although many of these were minor, $8 \%$ had chemotherapy altered because of these side effects. This compares with an overall incidence of $10 \%$, with $5 \%$ requiring changes in treatment in the British Thoracic Association's recent six-month chemotherapy trial. ${ }^{3}$ In its previous short-course chemotherapy trial the EHR/HR regimen had been altered in $4 \%$ because of unwanted effects, and $8 \%$ of those receiving SHR/HR had had to have the streptomycin substituted by ethambutol. ${ }^{9}$ Part of the reason for the higher figures seen in our survey was our low threshold of recording side effects while reviewing notes, but it also appeared to us that some physicians had a low threshold for altering treatment in routine hospital practice. Another explanation for the differences in the alteration of drug regimens would be a high threshold before changing regimens during a trial.

We thank the many physicians and surgeons who allowed us access to the case notes of patients in their care; the medical records staff in the areas; Mr P Samuel, department of medical statistics, Welsh National School of Medicine; the medical officers for environmental health, the Welsh Office and Dr P A Jenkins of the Mycobacterium Reference Unit, Cardiff, for helping us to trace the cases of tuberculosis; and Mrs K H Chaloner, Mrs P Davies, and Mrs M C Rowe for their secretarial help.

\section{References}

${ }^{1}$ British Thoracic and Tuberculosis Association. Short course chemotherapy in pulmonary tuberculosis. Lancet 1976;ii:1102-4.

${ }^{2}$ Office of Population Censuses and Surveys. Population of area health authorities and health districts by age 1979. Health and Personal Social Services Statistics for Wales 1980;7:3.

${ }^{3}$ British Thoracic Association. A controlled trial of six months chemotherapy in pulmonary tuberculosis. Br $\mathcal{F}$ Dis Chest $1981 ; 75: 141-53$.

${ }^{4}$ Lees AW, Allen GW, Smith J, Tyrrell WF. Tuberculosis maintenance therapy with isoniazid and ethambutol. Lancet 1980;ii:796.

${ }^{5}$ Working Party on Tuberculosis. Report No 4. Scottish Pulmonary Tuberculosis Survey, 1980. (SMR 14.)

${ }^{6}$ Leff AR, Leff DR, Brewin A. Tuberculosis chemotherapy practices in major metropolitan health departments in the United States. Am Rev Respir Dis $1981 ; 123: 176-80$.

${ }^{7}$ Heffernan JF, Nunn AJ, Peto J, Fox W. Pulmonary tuberculosis in Scotland: A national sample survey and follow up (1968-70). Tubercle $1975 ; 56: 253-67$.

${ }^{8}$ Heffernan JF, Nunn AJ, Peto J, Fox W. Tuberculosis in Scotland: A national sample survey (1968-70). Tubercle 1976;57:161-75.

${ }^{9}$ British Thoracic and Tuberculosis Association. Short course chemotherapy in pulmonary tuberculosis. Lancet $1975 ; \mathrm{i}: 119-24$.

${ }^{10}$ Fox W, Mitchison DA. Short course chemotherapy for pulmonary tuberculosis. Am Rev Respir Dis 1975;111:325-53.

(Accepted 8 October 1981)

\section{Miniprint pages}

If you want to read in full size the articles that appear in miniprint in your edition of the $B M \mathcal{F}$ you may:

- Change your edition of the journal. If you want to read practice observed articles regularly you need the Practice Observed edition; if you want to read clinical research articles you need the Clinical Research edition.*

- Write to the publishing department for a full-sized copy of an individual article that appears in miniprint in your edition.

- Take advantage of the journal's special offer on magnifying glasses. Some of these are still available (price $£ 1.50$ including post and packaging) from the publishing department.
- Subscribe to a set of full-size pages to be sent at the end of each month. This service (subscription $£ 10$ a year) is designed mainly for readers who want to bind their journals.

- Arrange among your colleagues (in a group practice or hospital department, for example) for one person to subscribe to the alternative edition of the $B M \mathcal{F}$. Then everyone in the group will have access to both editions.

The editorial content of both editions is the same: the only difference is in the size of the print of the clinical research and practice observed sections. 